\title{
Supramolecular Drug Inclusion Complex Constructed from Cucurbit[7]uril and the Hepatitis B Drug Adefovir
}

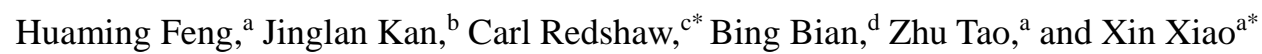

${ }^{a}$ Key Laboratory of Macrocyclic and Supramolecular Chemistry of Guizhou Province, Guizhou University, Guiyang 550025, China

${ }^{b}$ College of Chemistry, Chemical Engineering and Materials Science, Collaborative Innovation Center of Functionalized Probes for Chemical Imaging in Universities of Shandong, Key Laboratory of Molecular and Nano Probes, Ministry of Education, Shandong Normal University, Jinan 250014, China

${ }^{c}$ Chemistry, School of Mathematics and Physical Sciences, University of Hull, Hull HU6 7RX, U.K.

${ }^{d}$ College of Chemistry and Environmental Engineering, Shandong University of Science and Technology, Qingdao 266590, China.

Abstract: The interaction between cucuribit[7]uril (Q[7]) and Adefovir (ADV) has been studied in aqueous solution by ${ }^{1} \mathrm{H}$ NMR spectroscopy, electronic absorption spectroscopy, Isothermal Titration Calorimetry and mass spectrometry. The results revealed that an inclusion complex was formed via encapsulation of the purine rings of the guest ADV, while the phosphonomethoxyethyl group was prevented from entering the cavity. ITC data revealed that the formation of this 1:1 inclusion complex is mainly driven by favourable enthalpy changes. Studies investigating the release of ADV from the inclusion complex revealed enhanced rates under acidic conditions, although the rates were slower than observed for the free guest under the same 
conditions. Thermal stability studies indicated that the included form of ADV was more stable that the free form.

\section{Introduction}

Adefovir (ADV) was originally of interest in the 1990s for the treatment for HIV, but complications with dosage size versus kidney problems led to its withdrawal by the FDA. [1] However, the use of lower dosages proved fruitful for the treatment of hepatitis B, and in the early 2000s, Adefovir was approved for use. [2] The medicinal potential of compounds such as Adefovir can be broadened and/or improved if delivery to specific targets in the body is achieved without degradation. With this in mind, we are interested in the host-guest properties of cucurbit $[n]$ urils, $\mathrm{Q}[n] \mathrm{s}$, which given their enhanced solubility, recognition properties, ability to cross cell membranes and favorable toxicity profiles are attractive as containers/scaffolds for drug delivery. [3] This is exemplified by the work of Isaacs et al who have made use of cucurbit[7]uril to deliver oxaliplatin to cancer cells, [4] whilst Wang et al reported reduced toxicity but preservation of anticancer activity for Q[7] encapsulated camptothecin. [5] The host-guest complex formed between Q[7] and oxaliplatin demonstrated enhanced antitumour activity (using colorectal cells) versus only oxaliplatin, which illustrated the potential for supramolecular chemotherapy. [6] There is also potential for such an approach to be employed in the war against neurodegenerative diseases, such as Parkinson's disease. [7] Other complexation studies on $\mathrm{Q}[n]$ s and multinuclear platinum complexes suggested that Q-based 
scaffolds can, via encapsulation, provide steric hinderance to drug degradation and thus have potential for pharmacological delivery. [8] Other work by Zheng and Wang has reported how the presence of Q[7] can improve the in-vitro and in-vivo uptake of the dye molecule coumarin-6; [9] coumarin forms a 1:1 inclusion complex with Q[7] but a 2:1 complex with Q[8]. [10] Other drugs such as atenolol, glibenclamide, memantine and paracetamol can be stabilized in the solid state by forming inclusion complexes with Q[7], [11] whilst increased stability (2 to 3x versus similar sized $\beta$-cyclodextrin) constants are observed for the anaesthetics procaine, tetracaine, procainamide, dibucaine and prilocaine in aqueous solution. [12] The histamine $\mathrm{H}_{2}$-receptor antagonist rantidine has also exhibited increased stability in acidic aqueous solution in the presence of Q[7], [13] as did the antituberculosis drugs pyrazinamide and isoniazid. [14] Furthermore, the problematic cardiotoxicity of the antituberculosis drug clofazimine can be almost completely eliminated by complexation with Q[7]. [15] It is against this background that we now report our findings on the interaction of Q[7] with Adefovir (ADV) (see Scheme 1). Results are compared against out earlier study of the pro-virucide Adefovir bis(L-leucine propyl)ester (PMEA-Leu) - see scheme 1, left. [16] 

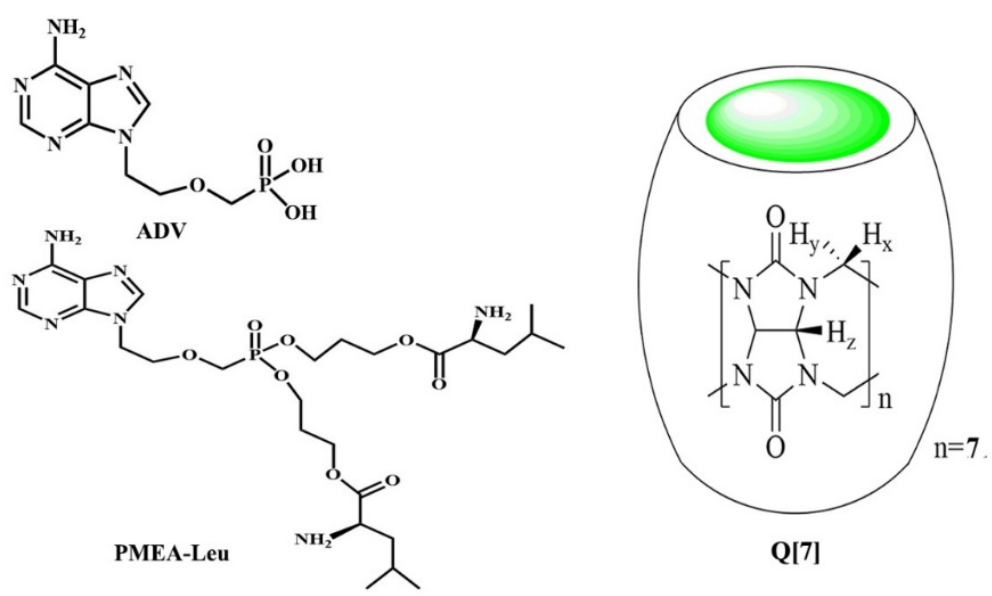

Scheme 1. Schematic molecular structures of ADV, PMEA-Leu and Q[7].

\section{Results and Discussion}

\subsection{NMR spectroscopy}

In order to investigate the complexation of Q[7] with $\mathrm{ADV}$ in solution, ${ }^{1} \mathrm{H}$ NMR spectroscopic titration experiments were first performed by adding increasing amounts of Q[7] into the solution of ADV in $\mathrm{D}_{2} \mathrm{O}$. A slight up-field shift of the signals of the protons of the purine ring was observed when Q[7] was added, and these up-field shifts of the purine ring proton signals can be classified into $\mathrm{Ha}$ and $\mathrm{Hb}$. The resonance of the protons $\mathrm{Ha}$, and $\mathrm{Hb}$ experience upfield shifts of $0.59 \mathrm{ppm}$ and 0.73 ppm, while the resonances of protons Hc, and Hd associated with the alkyl chain exhibited up-field shifts of $0.55 \mathrm{ppm}$ and $0.39 \mathrm{ppm}$, respectively. By contrast, the resonance of the proton He experiences a downfield shift of $0.48 \mathrm{ppm}$ when the ratio of $A D V / Q[7]$ reaches 1:1.57. These shift observations indicate that the purine rings were all accommodated within the cavity of Q[7], whereas the phosphonomethoxyethyl was prevented from entering the cavity. These results differ from our early observations for the pro-virucide Adefovir bis(L-leucine propyl)ester (PMEA-Leu), [16] where the two ends of the branches (ie. the leucine propyl groups) 
of PMEA-Leu (see scheme 1) were included in the Q[7] cavity. Thus, in the case of the interaction between PMEA-Leu and Q[7], the situation is best described as a partial inclusion complex.

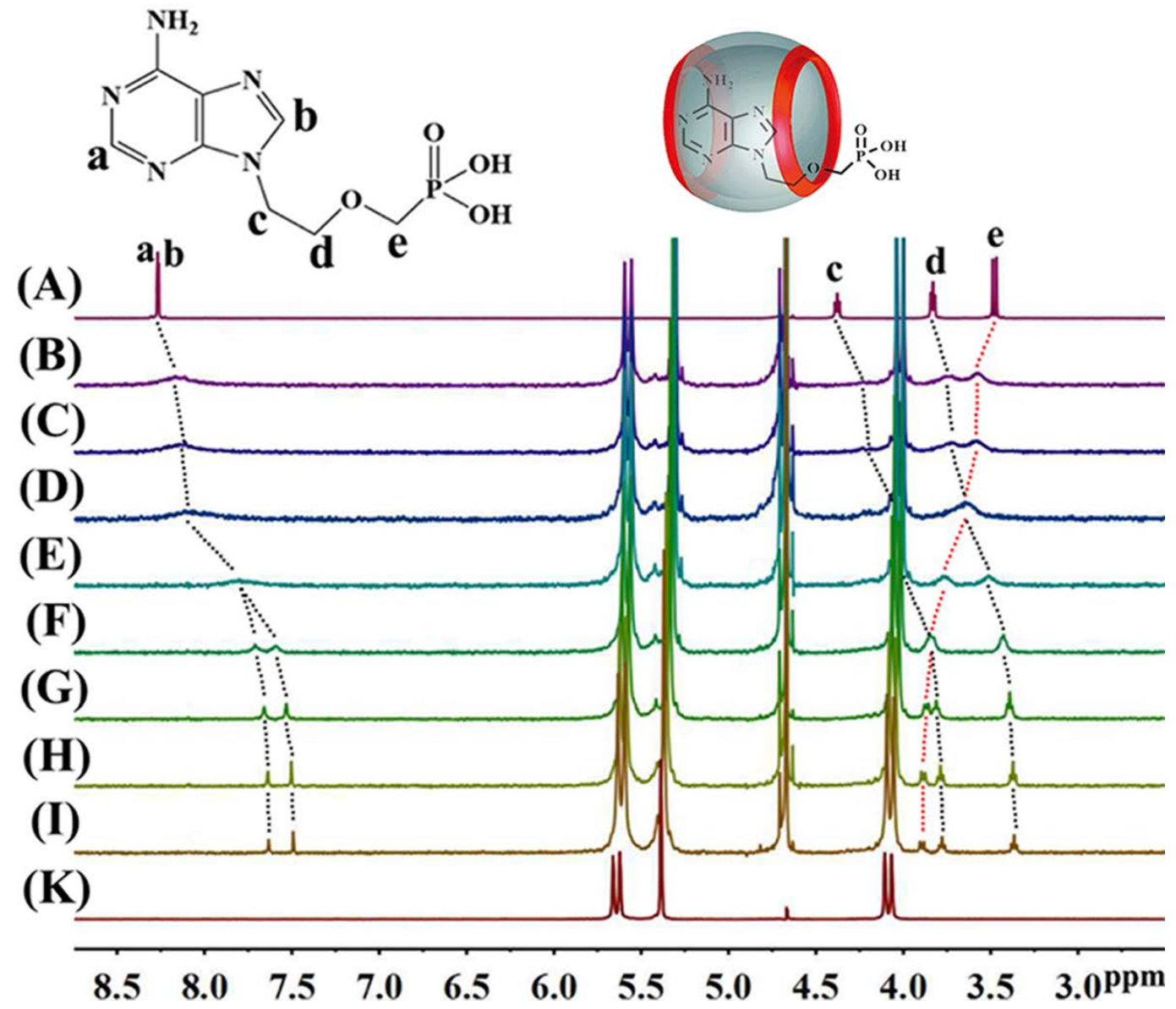

Figure 1. ${ }^{1} \mathrm{H}$ NMR spectra of ADV (A), ADV and Q[7] in the ratio of 0.30 (B), 0.36 (C), 0.47(D), $0.90(\mathrm{E}), 1.0(\mathrm{~F}), 1.08(\mathrm{G}), 1.38(\mathrm{H}), 1.57(\mathrm{I})$ and $\mathrm{Q}[7](\mathrm{K})$ in $\mathrm{D}_{2} \mathrm{O}$

\section{UV absorption spectroscopy}

The supramolecular interactions of the Q[7]/ADV host-guest inclusion complex were then further investigated by the use of UV spectroscopy. As shown in Figure 2A and B, the drug ADV exhibited a maximum UV absorption at $261 \mathrm{~nm}$ in aqueous media, whilst Q[7] exhibited no absorbance in the range $\geq 210 \mathrm{~nm}$. On addition of increasing amounts of the host Q[7] to ADV at a fixed ADV concentration of $4.0 \times 10^{-5} \mathrm{M}$, the This is an Accepted Manuscript of an article published by Taylor \& Francis in Supramolecular Chemistry on 25 December 2018, available online: http://www.tandfonline.com/10.1080/10610278.2018.1562193. 
absorption spectra of the ADV became weaker. These observations indicate that the interaction between $\mathrm{Q}[7]$ and $\mathrm{ADV}$ has occurred. Furthermore, in Figure 2C the stoichiometry was confirmed by a Job's plot, and the UV data can be fitted to a 1:1 binding model.
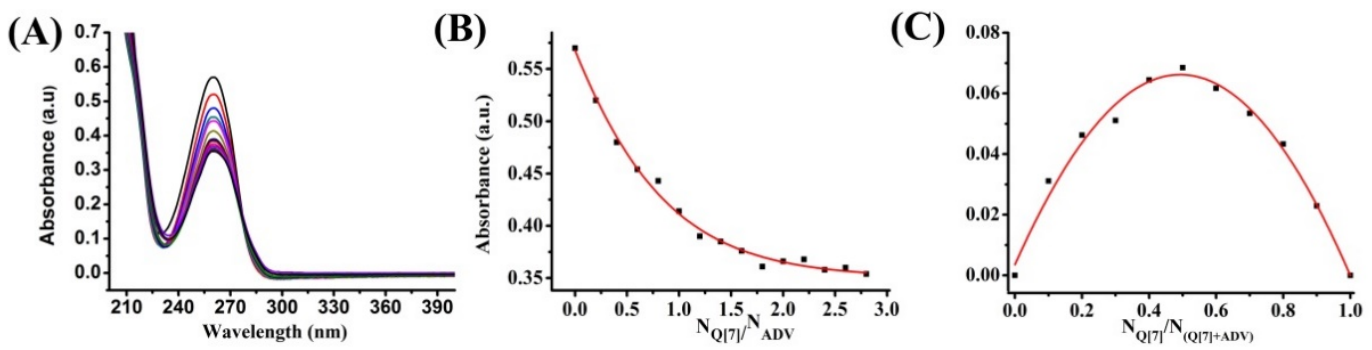

Figure 2. UV absorption of ADV $\left(4.0 \times 10^{-5} \mathrm{~mol} \cdot \mathrm{L}^{-1}\right)$ upon the addition of increasing amounts $(0$, $0.1,0.2 \ldots .2 .6,2.8$ equiv) of Q[7] (A), the concentrations and the corresponding $\Delta A$ vs. $N_{i \mathrm{Q}[7]} / N_{\mathrm{ADV}}$ curve (B) and the $\Delta \mathrm{A} \sim N_{\mathrm{Q}[7]} / N_{\mathrm{Q}[7]+} N_{\mathrm{ADV}}$ curves (C).

\section{Isothermal Titration Calorimetry}

To study the thermodynamics parameter of the complexation between ADV and Q[7], we conducted ITC experiments at $298.15 \mathrm{~K}$ in pure water. The titration graphs and the thermodynamic parameters data are shown in Figure 3 and Table 1 respectively, and the experimental results revealed a $K_{\mathrm{a}}$ value of $(4.25 \pm 0.22) \times 10^{4} \mathrm{M}^{-1}$. This $K_{\mathrm{a}}$ value is indicative of effective binding between ADV and Q[7]. Furthermore, the negative enthalpy variation, $\Delta H^{\circ}=(-29.05 \pm 0.13) \mathrm{kJ} \cdot \mathrm{mol}^{-1}$ and the negative entropy variation, $T \Delta S^{\circ}=(-2.41 \pm 0.26) \mathrm{kJ} \cdot \mathrm{mol}^{-1}$, indicate that the formation of the inclusion complex between $\mathrm{ADV}$ and Q[7] is mainly driven by favourable enthalpy changes, accompanied by small negative (unfavourable) entropy changes. 


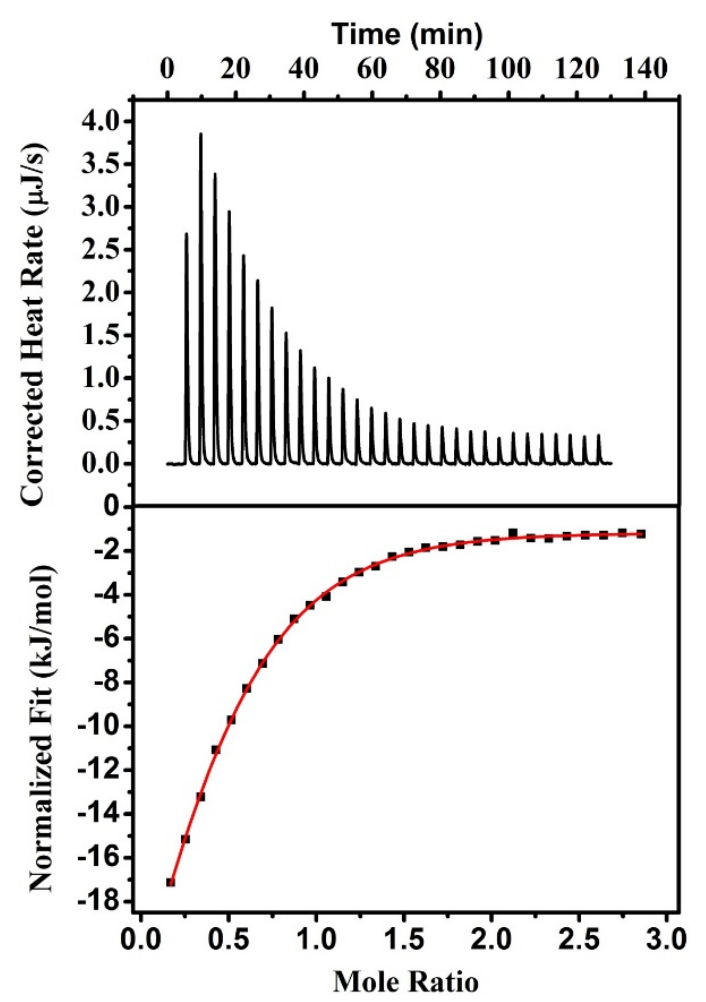

Figure 3 Isothermal titration calorimetry profiles of Q[7] with ADV in aqueous solution at 298.15 K. Nano ITC data for 30 sequential injections of ADV solution into TMeQ[7] solution (top). Apparent reaction heat obtained from integration of the calorimetric traces (bottom).

Table 1. The thermodynamic parameters of ADV/Q[7].

\begin{tabular}{ccccc}
\hline Complex & $n$ & $K_{\mathrm{a}}\left(\mathrm{M}^{-1}\right)$ & $\Delta H^{\circ}\left(\mathrm{kJ} \mathrm{mol}^{-1}\right)$ & $T \Delta S^{\circ}\left(\mathrm{kJ} \mathrm{mol}^{-1}\right)$ \\
\hline $\mathrm{ADV} / \mathrm{Q}[7]$ & 1.07 & $(4.25 \pm 0.22) \times 10^{4}$ & $(-29.05 \pm 0.13)$ & $(-2.41 \pm 0.26)$ \\
\hline
\end{tabular}

\section{MALDI-TOF mass spectrometry}

Analysis of the inclusion complex by MALDI-TOF mass spectrometry revealed (see Figure 4) an intense signal at $\mathrm{m} / \mathrm{z}=1436.01$, which corresponds to $\mathrm{ADV} / \mathrm{Q}[7]$ (calculated 1435.53), thereby providing direct support for the formation of the 1:1 stoichiometry for the host-guest inclusion complex ADV/Q[7]. 


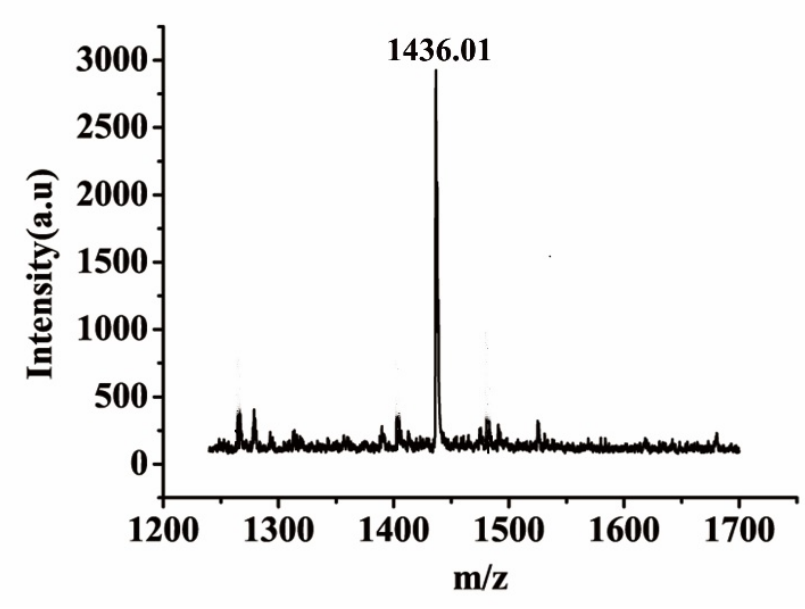

Figure 4. MALDI-TOF mass spectrum of the complex ADV/Q[7].

\section{Controlled release behaviour}

To understand the controlled release performance of this inclusion complex, the ADV release from inclusion complex $\mathrm{ADV} / \mathrm{Q}[7]$ was investigated in water at $37{ }^{\circ} \mathrm{C}$ (Figure 5). The ADV and ADV/Q[7] are released, via the use of a dialysis bag (for full details see experimental section), on an orbital oscillator and the solution curve for drug release is obtained based on the solution absorption of the drug at different times (Figure 5). When the solution $\mathrm{pH}$ was kept at 6.8 using a $\mathrm{NaH}_{2} \mathrm{PO}_{4} / \mathrm{Na}_{2} \mathrm{HPO}_{4}$ buffer, the ADV was totally released after 25 min. Whereas, in the case of the inclusion complex ADV/Q[7], the ADV was released from the Q[7] over $145 \mathrm{~min}$, which indicated that the release time of ADV from the inclusion complex was longer than that in the case of the free guest. The released amounts of ADV and $\mathrm{ADV} / \mathrm{Q}[7]$ were respectively $57.8 \%$ and $58.2 \%$. When the $\mathrm{pH}$ was about 1.2 , the ADV was totally released after 35 min., whilst ADV was released from Q[7] showed over 85 min.; the released amounts of ADV and ADV/Q[7] were 48.7\% and 45.1\% respectively (Figure 6). In short, these results indicate that the $\mathrm{pH}$ of the solvent medium can act as a trigger for release, ie for the free drug, the released amounts This is an Accepted Manuscript of an article published by Taylor \& Francis in Supramolecular Chemistry on 25 December 2018, available online: http://www.tandfonline.com/10.1080/10610278.2018.1562193. 
of $\mathrm{ADV}$ at $\mathrm{pH} 6.8$ was more than at $\mathrm{pH} 1.2$, and similarly for the ADV/Q[7] complex, at $\mathrm{pH}$ 6.8, both the release time and the amounts of drug was more than at $\mathrm{pH} 1.2$.

(a)

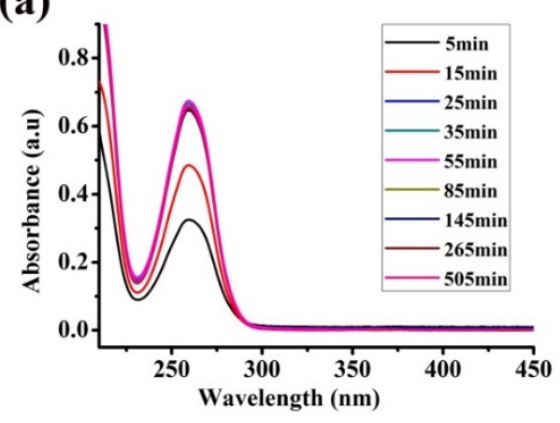

(b)

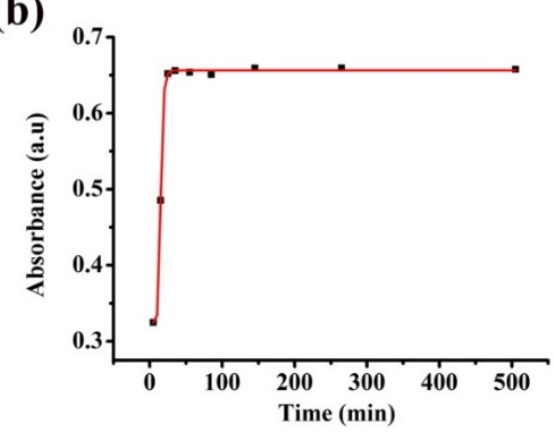

(d)

(c)

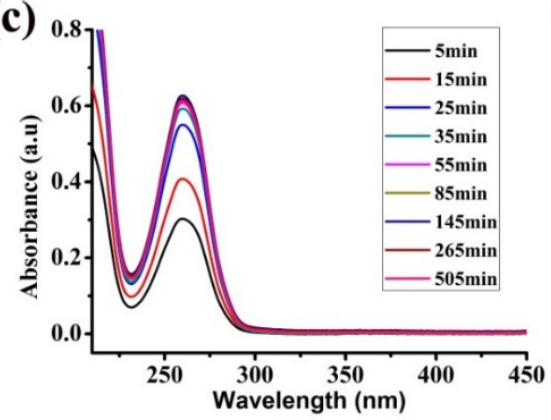

(e)

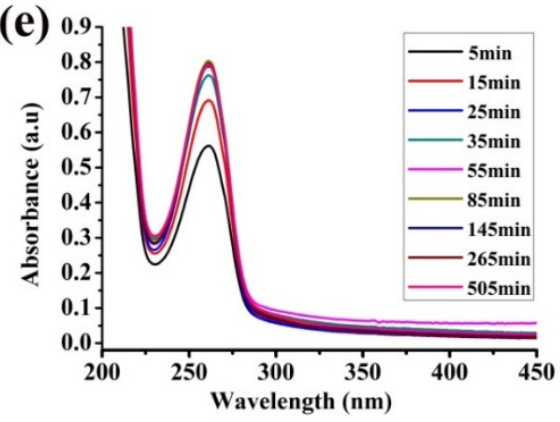

(g)

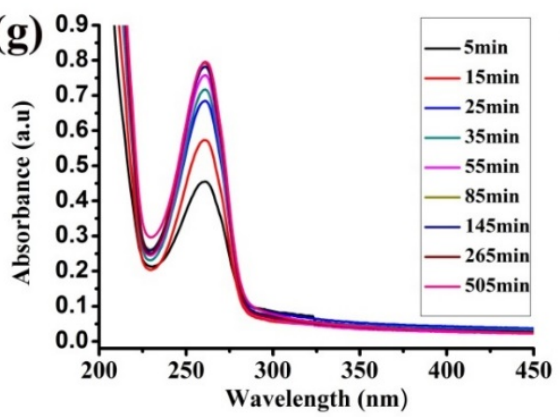

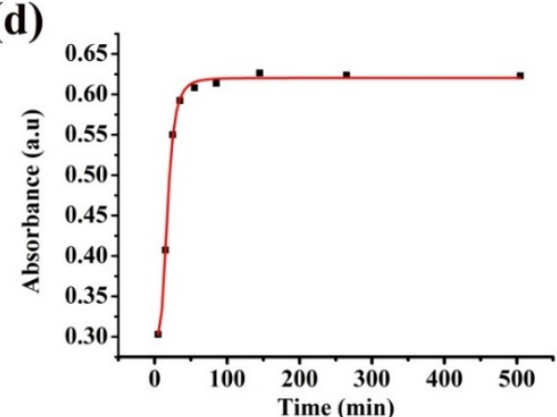
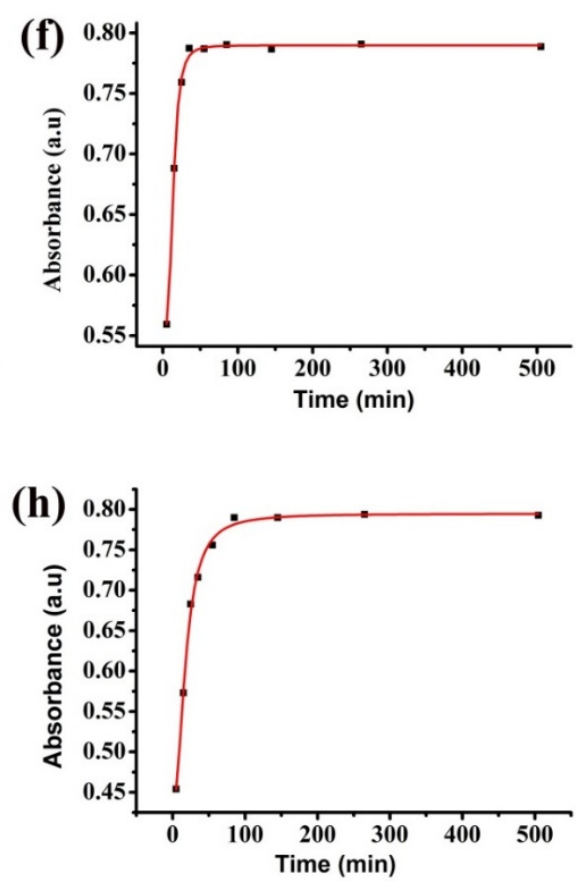

Figure 5. The UV absorption changes in the release for free guest ADV at $\mathrm{pH}=6.8(\mathrm{a}, \mathrm{b})$, inclusion complex ADV/Q[7] at $\mathrm{pH}=6.8(\mathrm{c}, \mathrm{d})$, free guest $\mathrm{ADV}$ at $\mathrm{pH}=1.2(\mathrm{e}, \mathrm{f})$ and inclusion complex ADV/Q[7] at $\mathrm{pH}=1.2(\mathrm{~g}, \mathrm{~h})$ in water. 

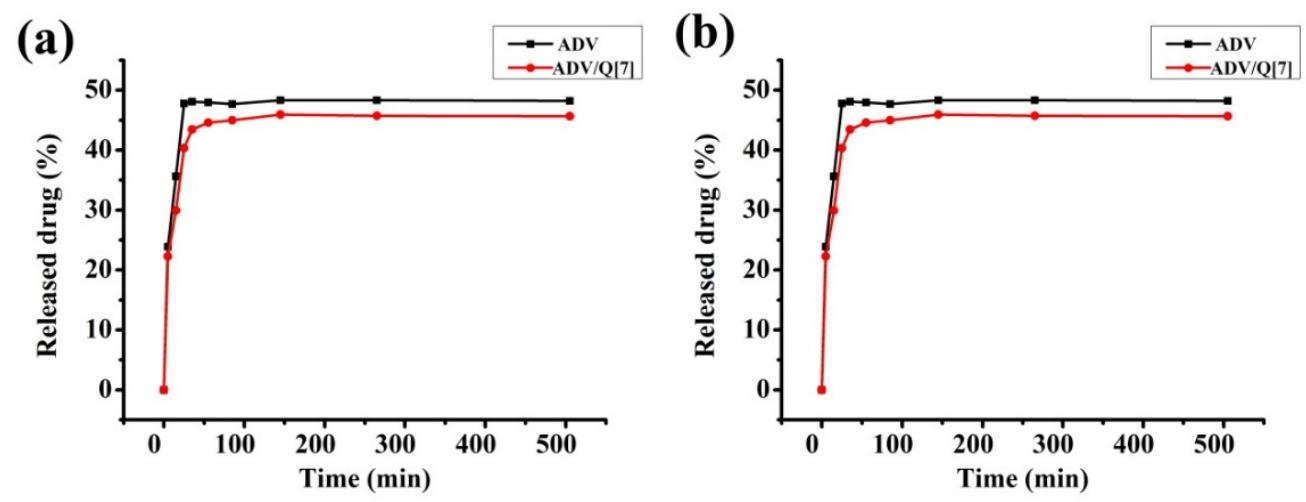

Figure 6. The release curves obtained for free guest $\mathrm{ADV}$ and inclusion complex ADV/Q[7] at $\mathrm{pH}$ $=6.8(\mathrm{a})$, and $\mathrm{pH}=1.2(\mathrm{~b})$ in water.

\section{Thermal stability analysis}

From the DTA spectra (Figure 6), it is also evident that ADV and Q[7] interacted with each other. Analysis of the thermal stabilities is via the use of differential scanning calorimetry (DSC) and thermogravimetry (TG). As shown in Figure 7, Q[7] has a broad endothermic peak at $402.1^{\circ} \mathrm{C}$ typical of an amorphous material, and crystalline ADV has a sharp melting endothermic peak at $306.1^{\circ} \mathrm{C}$. Whilst for the ADV/Q[7] inclusion complex a clear melting point endothermic peak is observed at $395.1^{\circ} \mathrm{C}$. The results are consistent with the formation of a new material with improved thermal stability of ADV.

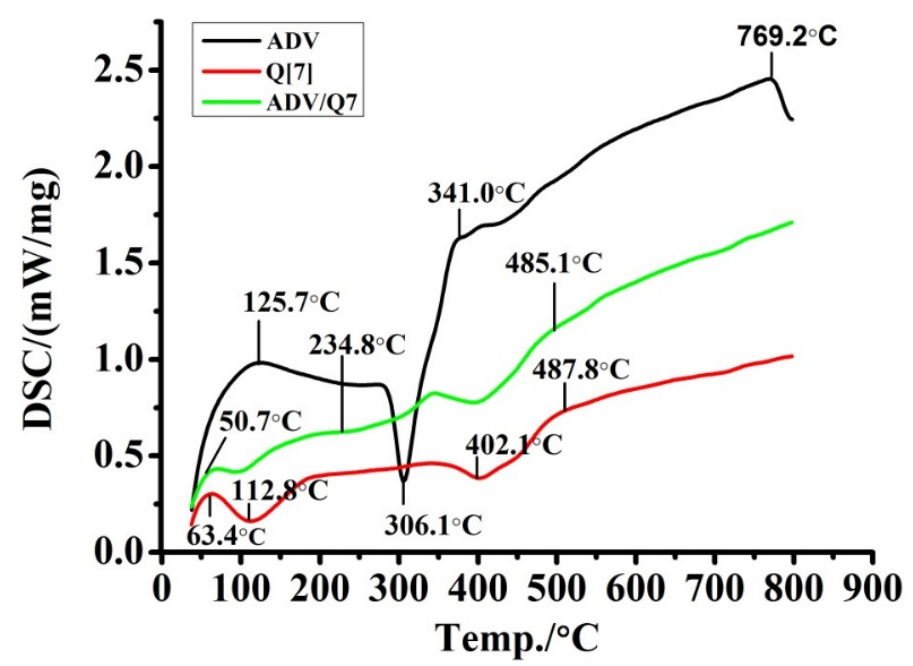

Figure 7. DSC spectra of ADV, Q[7] and inclusion complex ADV/Q[7]. 


\section{Conclusion}

We have investigated the interaction between cucuribit[7]uril (Q[7]) and the hepatitis B drug Adefovir by a variety of techniques such as ${ }^{1} \mathrm{H}$ NMR spectroscopy, electronic absorption spectroscopy, Isothermal Titration Calorimetry and mass spectrometry. At an $\mathrm{ADV}: \mathrm{Q}[7]$ ratio in excess of 1:1, NMR observations indicate that the guest purine rings are encapsulated by the Q[7], whilst the phosphonomethoxyethyl was prevented from entering the cavity. ITC results indicate that the formation of the 1:1 inclusion complex is mainly driven by favourable enthalpy changes. The controlled release of ADV from this inclusion complex was investigated in water at $37^{\circ} \mathrm{C}$ at pHs 6.8 and 1.2 using an orbital oscillator. The release was faster under more acidic conditions, though in both cases the process was slower than that observed for the free guest. Analysis of the starting materials and the inclusion complex by differential scanning calorimetry (DSC) indicated that the new inclusion compound afforded a form of ADV that was more thermally stable than the free guest. These studies suggest there is potential to use Q[7] to enhance the stability of ADV-type molecules and to control the release of such drug molecules by manipulation of the $\mathrm{pH}$ employed. Further studies are on-going in our laboratory to investigate the ability of Q[7] to act as a scaffold for other drug molecules.

\section{Experimental}

\section{Materials and apparatus}

The host Q[7] was prepared according to the literature method. [16] Adefovir (ADV) was obtained from Aldrich and was used without further purification. All other 
reagents were of analytical grade and were used as received. Double-distilled water was used for all experiments.

Preparation of ADV/Q[7]: The required amounts of Q[7] and ADV were respectively

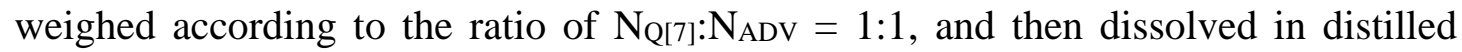
water and stirred for $30 \mathrm{~min}$. The solvent was then evaporated to afford the 1:1 inclusion compound ADV/Q[7].

\section{${ }^{1}$ H NMR spectroscopy}

To study the host-guest complexation of $\mathrm{Q}[7]$ and ADV, all the ${ }^{1} \mathrm{H}$ NMR spectra, including those for the titration experiments, were recorded at $298.15 \mathrm{~K}$ on a JEOL JNM-ECZ400S $400 \mathrm{MHz}$ NMR spectrometer (JEOL) in $\mathrm{D}_{2} \mathrm{O} . \mathrm{D}_{2} \mathrm{O}$ was used as a field-frequency lock, and the observed chemical shifts are reported in parts per million (ppm). The concentration of Q[7] employed in the NMR experiments was1.0 $\times 10^{-4} \mathrm{~mol} / \mathrm{L}$.

\section{UV-vis Absorption measurements}

UV-vis absorption spectra of the host-guest complexes were recorded using an Agilent 8453 spectrophotometer at room temperature. The aqueous solution of ADV was prepared with a concentration of $1.00 \times 10^{-3} \mathrm{~mol} / \mathrm{L}$. An aqueous solution of Q[7] was prepared with a concentration of $1.00 \times 10^{-3} \mathrm{~mol} / \mathrm{L}$ for absorption spectra determination. The UV-vis absorption experiments were performed as follows: 400 $\mu \mathrm{L}$ of a $1.00 \times 10^{-3} \mathrm{~mol} / \mathrm{L}$ stock solution of adefovir and various amounts of an aqueous $1.0 \times 10^{-3} \mathrm{~mol} / \mathrm{L} \mathrm{Q}$ [7] solution were transferred into a $10 \mathrm{~mL}$ volumetric flask, and then the volumetric flask was filled to the final volume with distilled water. The $\mathrm{pH}$ was adjusted to $\mathrm{pH}=7$ with sodium phosphate. Samples of these solutions were combined to give solutions with an $\mathrm{ADV}: \mathrm{Q}[7]$ ratio of $0,0.1,0.2,0.3,0.4,0.5 \ldots \ldots$ and 2.8. The formation constants of the ADV@Q[7] complexes (K) (1:1) were calculated according to curve fitting method. The Jobs plot method was used to determine the inclusion ratio of the substance, $\left.\mathrm{N}_{\mathrm{Q}[8]}: \mathrm{N}_{(\mathrm{Q}[7]}+\mathrm{ADV}\right)=0,0.1,0.2,0.3, \ldots, 1.0$.

\section{Isothermal titration calorimetry (ITC) experiments}

Microcalorimetric experiments were conducted using an isothermal titration 
calorimeter Nano ITC 2G (TA, USA). The amount of heat released was recorded at 298.15 K. The solution of Q[7] $\left(1.00 \times 10^{-4} \mathrm{~mol} / \mathrm{L}\right)$ was added to a small amount of thermal reaction cell $(1.3 \mathrm{~mL})$ and the free solution $\left(1.00 \times 10^{-3} \mathrm{~mol} / \mathrm{L}\right)$ was continuously injected into the syringe $(250 \mu \mathrm{L})$. The dilution heat-corrected reaction of the guest solution was determined in a separate experiment. All solutions were degassed by sonication prior to the titration experiments. Computer simulations (curve fitting) were performed by using the Nano ITC analysis software.

\section{In vitro release studies}

The in vitro drug release behavior of the inclusion compound was investigated on an orbital oscillator. The $2.7 \mathrm{mg} \mathrm{ADV}$ and $14.3 \mathrm{mg}$ ADV/Q[7] $\left(\mathrm{N}_{\mathrm{ADV}}: \mathrm{N}_{\mathrm{Q}}[7]=1: 1\right)$ inclusion compound were weighed accurately and then placed on a dialysis bag respectively, and next the sample bags were placed in an orbital oscillator containing artificial intestinal fluid ( $\mathrm{pH}=6.8$ phosphate buffer solution) or artificial gastric juice ( $\mathrm{pH}=1.2$ ) hydrochloric acid solution). To this was added an equivalent of hydrochloric acid containing $0.09 \% \mathrm{Na}^{+}$ion, which was shaken slowly in a water bath at $37^{\circ} \mathrm{C}$. At regular time intervals, $1 \mathrm{~mL}$ of the sample was removed, whilst at the same time adding the same volume of the new buffer solution. The absorbance of the sample was measured at $260 \mathrm{~nm}$.

\section{Acknowledgements}

The Natural Science Foundation of China (21861011), the Major Program for Creative Research Groups of Guizhou Provincial Education Department (2017-028), the Innovation Program for High-level Talents of Guizhou Province (No. 2016-5657) and Science and Technology Project of Guizhou Province (2018-5781) are gratefully 
acknowledged for financial support. CR thanks the EPSRC for a travel grant (EP/L012804/1).

\section{References}

[1] E. J. Fisher, K. Chaloner,D. L. Cohn, L. B. Grant, B. Alston, C. L. Brosgart, B. Schmetter, W. M. El-Sadr, J. Sampson, AIDS, 2001, 15, 1695-1700.

[2] P. Marcellin, T.-T. Chang, S. G. Lim, M. J. Tong, W. Sievert, M. L. Shiffman, L. Jeffers, Z. Goodman, M. S. Wulfsohn, S. Xiong, J. Fry and C. L. Brosgart, N. Engl. J. Med. 2003, 348, 808-816.

[3] (a) P. Montes-Navajas, M. González-Béjar, J. C. Scaiano and H. García, Photochem. Photobiol. Sci. 2009, 8, 1743-1747. (b) G. D. Ma, L. Isaacs and V. Briken, PLoS ONE, 2010, 5, e10514. (c) V. D. Uzunova, C. Cullinane, K. Brix, W. M. Nau and A. I. Day, Org. Biomol. Chem. 2010, 8, 2037-2042. (d) G. Parvari, O. Reany, and E. Keinan, Isr. J. Chem. 2011, 51, 646-663. (e) K. I. Kuok, S. Li, I. W. Wyman, and R. Wang, Ann. N.Y. Acad. Sci. 2017, 1398, 108-119. (f) M. J. Webber and R. Langer, Chem. Soc. Rev. 2017, 46, 6600-6620. (g) X. Yang, W. Zhao, Z. Wang, Y. Huang, S. M. Y. Lee, Z. Tao, R. Wang, Food and Chemical Toxicology 2017, 108, 510-518. (h) X. Zhang, X. Xu, S. Li, L. Wang, J. Zhang, R. Wang, Scientific Reports, 2018, 8, 8819.

[4] L. Cao, G. Hettiarachchi, V. Briken, and L. Isaacs, Angew. Chem. Int. Ed. 2013, 52, $12033-12037$.

[5] X. Yang, Z. Wang, Y. Niu, X. Chen, S. M. Y. Lee and R. Wang, Med. Chem. Commun. 2016, 7, 1392-1397. 
[6] Y. Chen, Z. Huang, H. Zhao, J.-F. Xu, Z. Sun, and X. Zhang, ACS Appl. Mater. Interfaces 2017, 9, 8602-8608.

[7] S. Li, H. Chen, X. Yang, D. Bardelang, I. W. Wyman, J. Wan, S. M. Y. Lee, and R. Wang, ACS Med. Chem. Lett. 2015, 6, 1174-1178.

[8] (a) N. J. Wheate, D. P. Buck, A. I. Day and J. G. Collins, Dalton Trans. 2006, 451-458. (b) N. J. Wheate, J. Inorg. Biochem. 2008, 102, 2060-2066. (c) Q. Huang, K.I. Kuok, X. Zhang, L. Yue, S. M. Y Lee, J. Zhang, R. Wang, Nanoscale, 2018, 10, 10333-10336.

[9] X. Miao, Y. Li, I. Wyman, S. M. Y. Lee, D. H. Macartney, Y. Zheng and R. Wang, Med. Chem. Commun. 2015, 6, 1370-1374.

[10] R. Wang, D. Bardelang, M. Waite, K. A. Udachin, D. M. Leek, K. Yu, C. I. Ratcliffe and J. A. Ripmeester, Org. Biomol. Chem. 2009, 7, 2435-2439.

[11] F. J. McInnes, N. G. Anthony, A. R. Kennedy and N. J. Wheate, Org. Biomol. Chem. 2010, 8, 765-773.

[12] I. W. Wyman and D. H. Macartney, Org. Biomol. Chem. 2010, 8, 247-252.

[13] R. Wang and D. H. Macartney, Org. Biomol. Chem. 2008, 6, 1955-1960.

[14] N. J. Wheate, V. Vora, N. G. Anthony and F. J. McInnes, J. Incl. Macrocycl. Chem. 2010, 68, 359-367.

[15] S. Li, J. Y.-W. Chan, Y. Li, D. Bardelang, J. Zheng, W. W. Yew, D. P.-C. Chan, S. M. Y. Lee and R. Wang, Org. Biomol. Chem., 2016, 14, 7563-7569.

[16] Y. Huang, X. -Z. Fu, S. -F. Xue, Q. -J. Zhu and G. Wei, Supramol. Chem. 2013, 25, 166-172. 
[17] (a) J. Kim, I. S. Jung, S. Y. Kim, E. Lee, J. K. Kang, S. Sakamoto, K. Yamaguchi and K. Kim, J. Am. Chem. Soc. 2000, 122, 540-541. (b) A. Day, A. P. Arnold, R. J. Blanch and B. Snushall, J. Org. Chem. 2001, 66, 8094-8100. 